Institute of $\mathbf{F}_{\text {ood and }} \mathbf{A}_{\text {gricultural }} \mathbf{S}_{\text {ciences }}$

\title{
Preventing Foodborne Illness:Listeriosis ${ }^{1}$
}

\author{
Keith R. Schneider, Renée M. Goodrich, and Dirk Sampath²
}

This is one in a series of facts sheets discussing common foodborne pathogens of interest to food handlers, processors and retailers.

\section{What causes a Listeria-associated foodborne illness?}

Listeria monocytogenes is the bacterium that causes the foodborne disease listeriosis. Listeriosis is classified as a foodborne infection and is one of several foodborne diseases that are often reported in the scientific and popular press. Listeriosis expresses itself in the affected person by means of septicemia, meningitis (or meningoencephalitis) and/or encephalitis. Pregnant women exposed to $L$. monocytogenes in the $2^{\text {nd }}$ or $3^{\text {rd }}$ trimesters and who have intrauterine or cervical infections, may spontaneously abort the fetus or produce a stillbirth. Influenza-type symptoms, which may include continuous fever usually will precede the aforementioned disorders. In the U.S., listeriosis affects about 2500 persons every year, with about 500 of those cases resulting in death.

\section{What type of bacterium is Listeria?}

Listeria monocytogenes is a small, Gram-positive non spore-forming, rod-shaped bacterium that uses flagella for movement. Listeria monocytogenes can grow in a variety of growth conditions such as temperatures ranging from $37^{\circ} \mathrm{F}$ to $104^{\circ} \mathrm{F}$ and a $\mathrm{pH}$ range from 5.6 to 9.8. The fact that this organism can grow at refrigeration temperatures and withstand slightly acid conditions (commonly found in some cheeses), makes its control difficult. Some research suggests large doses of Listeria can survive heat treatments of $170^{\circ} \mathrm{F}$. Despite the small number of cases reported each year, Listeria remains a major health concern in food and it is gaining more public recognition as a safety problem in foods because of its high mortality rate.

Some studies have shown that L. monocytogenes can be in the intestines of $1-10 \%$ of humans. $L$. monocytogenes has been found in 37 species of domestic and feral mammals, at least 17 species of birds, and in some species of fish and shellfish. $L$. monocytogenes is quite hardy and has been know to survive long periods in a food processing environment, especially around moist, unsanitized areas such as drains and air conditioning vents that develop condensate. Although it does not form spores, it is somewhat resistant to the deleterious effects of freezing, drying, and heat.

1. This document is FSHN03-6, one of a series of the Food Science and Human Nutrition Department, Florida Cooperative Extension Service, IFAS, University of Florida. Publication: June 2003. Please visit the EDIS Web Site at http://edis.ifas.ufl.edu.

2. K.R. Schneider, Ph.D., assistant processor; R.M. Goodrich, Ph.D. assistant professor; and D. Sampath, graduate student, all of the Food Science and Human Nutrition Department, Cooperative Extension Service, IFAS, University of Florida, Gainesville, FL 32611.

The Institute of Food and Agricultural Sciences is an equal opportunity/affirmative action employer authorized to provide research, educational information and other services only to individuals and institutions that function without regard to race, color, sex, age, handicap, or national origin. For information on obtaining other extension publications, contact your county Cooperative Extension Service office. Florida Cooperative Extension Service/Institute of Food and Agricultural Sciences/University of Florida/Christine Taylor Waddill, Dean. 


\section{How is the Listeria bacterium spread?}

Listeria is found widely in nature in such places as water, soil, infected animals, human and animal feces, raw and treated sewage, leafy vegetables, effluent from poultry and meat processing facilities, decaying corn and soybeans, improperly fermented silage, and normal and mastitic milk prior to pasteurization. It is mainly transmitted to humans by food. Other, but rare, means of transmission are plant to humans, animals to humans, air to humans, and human to human.

Newborn babies can acquire L. monocytogenes by transmission from mother to fetus when the fetus is still in the womb or directly at the time of birth. Direct contact with $L$. monocytogenes can cause lesions on the hands or arms, and has, in rare cases, been transmitted during sexual contact. Inhalation of L. monocytogenes has also been implicated as another route of infection, although this is atypical.

Listeria monocytogenes has been known to inhabit animal intestines without causing sickness. Since the animal would show no signs of any illness, it could spread to meat and dairy products without the knowledge of the producer. The organism is killed by cooking or other heating methods such as pasteurization, processes commonly used to produce ready-to-eat (RTE) foods. RTE foods may become contaminated after the final heat treatment.

\section{Symptoms of listeriosis}

Listeriosis is identified in hospital tests when $L$. monocytogenes is detected in blood, cerebrospinal fluid, the placenta or fetus, and other such normally sterile areas in the body.

In mild cases of listeriosis, such as occurs in otherwise healthy people, gastrointestinal symptoms may be the only symptoms that occur. The time from the initial symptoms to manifestation of serious illness is not known, but it is probably a few days to three weeks. Listeriosis in the affected person commonly produces fever, muscle aches. Headache, stiff neck, confusion, loss of balance, or convulsions may result if the bacteria invade the nervous system.

\section{Foods associated with Listeria monocytogenes:}

Raw milk, improperly pasteurized fluid milk, cheeses (particularly soft-ripened varieties), ice cream, raw vegetables, fermented raw-meat sausages, raw and cooked poultry, raw and cooked-sliced meats (all types), and raw and smoked fish may contain $L$. monocytogenes. It can grow at temperatures as low as $37^{\circ} \mathrm{F}$ and can increase its numbers on refrigerated foods.

Other foods which may contain Listeria monocytogenes are: RTE seafood, for example smoked fish and smoked mussels; pre-mixed raw vegetable salads like coleslaw; pre-cooked meat products eaten without further cooking such as pâtés, sliced deli meat, and cooked diced chicken (as used in sandwich shops.); unpasteurized milk or unpasteurized milk foods; soft-serve ice creams; and soft cheeses, such as traditional Mexican cheeses, Camembert and ricotta.

\section{High-risk populations for listeriosis}

Listeria monocytogenes can affect people differently. Healthy people may have few or no symptoms, while others might suffer a serious, life-threatening infection that could require hospitalization or might even result in death.

High-risk groups for listeriosis include:

- Pregnant women and their unborn babies (the fetus is at-risk).

- Newborn babies.

- Persons with weakened immune systems as a result of disease or illness such as:

- Cancer

- Leukaemia

- Diabetes

- Liver or kidney disease.

- HIV / AIDS (It has been estimated that persons suffering from AIDS are about 200-300 times more likely to be affected by listeriosis) 
- Autoimmune disease (e.g., lupus)

- Persons using prednisone or cortisone medication, as this can also suppress the immune system. Organ transplant patients are also included here.

- The elderly.

\section{Minimizing the risk of listeriosis in the plant or food establishment:}

\section{Sanitation methods:}

Clean: Use hot, soapy water and a sanitizer to wash the hands and food contact surfaces often. Wash the hands, cutting boards, dishes and utensils, after they come in contact with raw food. Clean liquid spills in the refrigerator, especially spills from products associated with $L$. monocytogenes such as luncheon meats and hot dogs. L. monocytogenes can grow slowly in the refrigerator and can easily be spread to previously uncontaminated areas through contact with containers, packages and other food items.

- Ensure employees wash hands before, during and after handling any food, particularly raw meat and poultry.

- All utensils, cutting boards and work surfaces should be sanitized before and after use, utilizing an approved sanitizing agent.

- Clean food contact surfaces such as refrigerator shelving if they come in contact with possible sources of L. monocytogenes contamination (i.e., purge from open packages of luncheon meats or hot dogs).

Separate: Treat all RTE foods, raw meat, poultry and seafood as possible sources of contamination. Keep these types of foods separate from items that traditionally do not get cooked or potentially can be eaten raw such as vegetables, fruits, breads, and other already-prepared, edible foods. This will reduce the chance of cross-contamination.

- The utensils used for raw and cooked foods should be separate.
- Store meats and other potential sources of contamination below food that are consumed raw.

- Rewrap open packages carefully or store in leak proof containers to prevent cross-contamination.

Cook: Heat foods to safe temperatures. People who are in the high risk groups for listeriosis should cook, until steaming hot, all luncheon meats, cold cuts, other deli-style meats, and poultry.

The 2001 FDA Food Code recommends to cook to an internal temperature of $165^{\circ} \mathrm{F}$ or above for 15 seconds for most potentially hazardous foods (refer to Section 3-4: Destruction of Organisms of Public Health Concern; Subpart 3-401 of the 2001 FDA Food Code for specific details on cooking temperatures).

Freezing or refrigeration will not kill $L$. monocytogenes, and it can grow and multiply in refrigerated storage. At the present time, proper cooking, preventing cross contamination of raw and cooked food, proper personal hygiene and good sanitation are the best measures to control Listeria. Recommendations to reduce the incidence of foodborne listeriosis include the following:

- Don't store food in the temperature danger zone between $4^{\circ} \mathrm{C}\left(40^{\circ} \mathrm{F}\right)$ and $60^{\circ} \mathrm{C}\left(140^{\circ} \mathrm{F}\right)$. The refrigerator should be at $4^{\circ} \mathrm{C}\left(40^{\circ} \mathrm{F}\right)$ or colder. All food should be refrigerated promptly.

- Completely cook or boil foods like hot dogs and poultry products until they become steaming hot.

- Don't consume raw, unpasteurized milk or its derived foods like raw milk cheese.

Storage: Try to limit room temperature exposure of food to 2 hours or less before returning perishables and RTE foods to the refrigerator or freezer.

- Cover all food to prevent cross-contamination.

- Place all cooked food in the refrigerator within one hour of cooking.

- Place uncooked meat, poultry, fish, or other raw products below cooked or RTE foods in the refrigerator to prevent cross-contamination. 
- Maintain the refrigerator temperature at or below $4^{\circ} \mathrm{C}$, and keep refrigerator clean.

- Observe strictly the "use by" or "best by" dates on refrigerated items.

\section{References}

http://www.cfsan.fda.gov/ mow/chap6.html

http://www.cdc.gov/od/oc/media/fact/lister.htm

http://www.ces.uga.edu/pubcd/b901-w.html

http://www.health.state.ny.us/nysdoh/consumer/

lister.htm

http://www.fsis.usda.gov/oa/pubs/lmtips.htm

http://www.cfsan.fda.gov/ dms/fc01-toc.html

http://www.inspection.gc.ca/english/corpaffr/

foodfacts/listeriae.shtml

http://mdchoice.com/Pt/Ptinfo/lister.asp

http://www.fsis.usda.gov/OA/topics/lmguide.htm 